\title{
Diabetic cardiomyopathy: factual or factoid?
}

\author{
Thiago Quinaglia' \\ Daniela C. Oliveira ${ }^{1}$ \\ José Roberto Matos-Souza ${ }^{1}$ \\ Andrei C. Sposito ${ }^{1}$
}

1. Subject of Cardiology, Faculty of Medical Sciences - State University of Campinas (Unicamp), Campinas, SP, Brasil

http://dx.doi.org/10.1590/1806-9282.65.1.69

\begin{abstract}
SUMMARY
Although long ago described, there is no established consensus regarding the real existence of Diabetic Cardiomyopathy (CMPDM). Due to its complex pathophysiology, it has been difficult for clinical and experimental research to establish clear connections between diabetes mellitus (DM) and heart failure (HF), as well as to solve the mechanisms of the underlying myocardial disease. However, the epidemiological evidence of the relationship of these conditions is undisputed. The interest in understanding this disease has intensified due to the recent results of clinical trials evaluating new glucose-lowering drugs, such as sodium-glucose transporter inhibitors 2, which demonstrated favorable responses considering the prevention and treatment of HF in patients with DM. In this review we cover aspects of the epidemiology of CMPDM and its possible pathogenic mechanisms, as well as, present the main cardiac phenotypes of CMPDM ( $H F$ with preserved and reduced ejection fraction) and implications of the therapeutic management of this disease.
\end{abstract}

KEYWORDS: Diabetes mellitus. Cardiomyopathies. Hypoglycemic agents. Heart failure.

\section{INTRODUCTION}

The diagnosis of diabetic cardiomyopathy requires the association of altered glucose metabolism and exclusion of coronary, valvular, hypertensive, congenital, viral, toxic, familial or infiltrative arterial diseases. This is unquestionable from the theoretical point of view and, despite the difficulty in demonstrating in practice, the diagnosis may be more common than one might suppose. The observation that there is an association of diabetes mellitus (DM) and heart failure dates back 64 years. In the 1950s, Lundbaek hypothesized a diabetic cardiomyopathy (MCPDM) and, in 1969, published the first description of the disease. Curiously, until today there are doubts as to their actual occurrence and circumstances that may trigger it. In this narrative review, we present the current evidence of MCPDM, the possible pathogenic mechanisms, the cardiac phenotype of the disease, as well as possible ways of treating and not treating this condition.

\section{EVIDENCE OF THE RELATIONSHIP BETWEEN DIABETES MELLITUS AND HEART FAILURE}

The diagnosis of heart failure (HF) occurs more frequently in patients with diabetes mellitus (DM) $)^{1-3}$ and, when it occurs, is associated with worse clinical outcomes than in non-diabetic patients with $\mathrm{HF}^{2-6}$. Among patients with type $2 \mathrm{DM}$, the prevalence of $\mathrm{HF}$ ranges from $19 \%$ to $26 \%$, and the incidence is also high regardless of other comorbidities, as al-

DATE OF SUBMISSION: $12-$ Oct-2018

DATE OF ACCEPTANCE: 26-Oct-2018

CORRESPONDING AUTHOR: Andrei C Sposito

Subject of Cardiology, Faculty of Medical Sciences, State University of Campinas (Unicamp), Campinas, SP, Brasil - CEP $13084-971$

Tel: 551935219590

Fax: 551935219580

E-mail: andreisposito@gmail.com 
ready demonstrated by the Framingham study ${ }^{7}$. Diabetic men aged 45-74 years had more than double the risk of developing HF than their non-diabetic peers during follow-up of up to 18 years old. And that risk seems to be even greater in women. Diabetic women are up to 5 times greater risk than patients who do not have DM. In heart failure cohorts, there is also a higher prevalence of patients with type $2 \mathrm{DM}$, of about $28 \%$, whether HF with ejection fraction (FE) preserved (HFEFp), or reduced (HFEFp) ${ }^{6}$. And the presence of DM implies a worse prognosis, leading to higher cardiovascular mortality (CV) and hospitalizations due to HF [risk ratio for HFEFp: 2.0 (1.702.36); and for HFEFp:1.60 (1.44-1.77); p-value for interaction: 0.0009]. There is, however, disagreement as to whether this worse prognosis would be associated with the occurrence of ischemic coronary artery disease $^{5}$.

Previous studies have shown a clear ratio between glycemic control and the incidence of heart failure. Elevations of $1 \%$ in $\mathrm{HbA1c}$ values are related to an $8 \%$ increase in the incidence of $\mathrm{HF}^{8}$. Conversely, in the UKPS study, the researchers demonstrated that for each $1 \%$ reduction in HbA1c there would be a $16 \%$ decrease in the risk of initiation of $\mathrm{HF}^{9}$. This bidirectional ratio occurs independently of blood pressure, body mass index, age or presence of coronary artery disease. However, the ratio is not exactly linear. Apparently, using the HbA1c cohort of $7.0 \mathrm{mg} / \mathrm{dl}$ there is a divergence of studies regarding the pattern of the glycemia ratio with the mortality of patients with HF that may be: "U" pattern" - in which there is an increase in mortality above and below this cohort; "J" pattern - in which there is a disproportionately greater increase for HbA1c levels above this cohort ${ }^{11}$; and inverse pattern - in which mortality is higher for patients with HbA1c below the cohort mentioned ${ }^{12}$. This ratio between glycemia and HF, as well as mortality in the HF patient, even with divergent patterns between studies, makes clear the link between DM and HF. However, these data do not allow us to distinguish whether glycemia and insulin resistance are only markers of severity or whether they actually contribute to the pathophysiology of HF. The concomitance of other $\mathrm{CV}$ risk factors and the complex pathophysiology of type 2 DM make it even more difficult to establish a clear and direct ratio between pathogens and cardiac and/or cardiovascular phenotypes of the diabetic patient.

\section{POSSIBLE MECHANISMS}

The impact of DM on the heart occurs by locally diverse pathways on the microcirculation and relaxation function of the sarcomere, and systemically by peripheral vascular disease, activation of the renin-angiotensin-aldosterone system (RAAS) and autonomic neuropathy. These mechanisms are established as a consequence of an exacerbated inflammatory state, endothelial lesion and perfusion abnormalities, together with unbalanced oxidative stress.

\section{Hyperglycemia}

Experimentally, endothelial cell mitochondria exposed to hyperglycemia may be injured or increase the production of reactive species of $\mathrm{O} 2$. Ultimately, this leads to dysfunction of nitric oxide synthases (NO), NO bioavailability, and consequently reduction of the production of the intracellular cyclic guanosine monophosphate (GMPc) ${ }^{13}$. Due to the decrease in intracellular kinase $\mathrm{G}$ (PKG) protein, there is loss of myocardial distensibility ${ }^{14}$ mediated by hypophosphorylation of the sarcomeric titin protein ${ }^{15}$. In humans, similar results were observed in cardiomyocytes of patients with aortic stenosis and DM who showed improvement in stiffness when submitted to PKG administration ${ }^{16}$. Hyperglycaemia also results in elevation of kinase C protein (PKC) in fibroblasts, which in turn increase collagen production and deposition $^{16,17}$.

Another route of action of hyperglycemia on cardiac function occurs by glucose metabolites. A $\beta$-N-acetylglucosamine (O-G1cNAc) can bind to a myriad of proteins (on serine or threonine residues), compete for phosphorylation of molecules, and alter physiological functions ${ }^{18}$. A pivotal example is the modification of kinase II proteins dependent on Ca2 +/calmodulin, phospholamban and myofilaments. This effect reduces contractility and relaxation of the myocardium ${ }^{19}$. Mitochondrial proteins are also susceptible to modification by O-G1cNAc with impairment to cardiac function.

\section{Insulin/hyperinsulinemia resistance}

Potential mediators of the risk of $\mathrm{HF}$ in patients with type $2 \mathrm{DM}$ are insulin and hyperinsulinemia resistance, particularly in the obese patient. The prevalence of obesity per se increases circulating levels of glucose and free fatty acids. In addition, insulin resistance and obesity are responsible for a constellation of signaling disorders, leading to a systemic inflam- 
matory state that results in the production of reactive species of $\mathrm{O}^{2}$ and decrease in the bioavailability of NO. Insulin resistance induces myocardial energy imbalance by increasing the use of less efficient sources to the detriment of glucose use, and this culminates with lower production of adenosine triphosphate (ATP) ${ }^{20,21}$. Hyperinsulinemia, in turn, activates certain pathways, such as PI3K/Akt, which is involved in hypertrophy of cardiomyocytes. This same pathway also induces the expression of a more rigid molecule of the sarcomeric titin protein, reducing cardiac distensibility ${ }^{22}$.

\section{Inflexibility of power supply}

Diabetic patients with coronary heart disease and those with HF may already have reduced glucose utilization capacity compared to non-diabetic HF patients, despite having a similar concentration of glucose transporters (GLUT-4) in myocardial biopsies. This theory suggests that insulin resistance would limit the ability of the DM patient's myocardium to withstand ischemia and, thus, suffer worse CV outcomes ${ }^{23}$. Studies using hyperinsulinemic/euglycemic clamp demonstrate that elevated insulin levels increase heart rate, blood pressure and myocardial oxygen consumption (assessed by extraction of Fluordeoxyglucose ${ }^{18}$ ) in diabetic patients or not. The presence of insulin reduces the availability of non-esterified fatty acids and suppresses oxidation of fatty acids. However, the oxidation of fatty acids by the myocardium is increased. Under these conditions, there is a reduction in myocardial work efficiency, possibly due to the change in the energy substrate (from glucose to fatty acid), since the fatty acid metabolism consumes a greater amount of oxygen ${ }^{24}$. In diabetic patients, the rapid and drastic reduction of free fatty acids by medication intervention leads to a sudden decrease in cardiac function, corroborating this hypothesis. Cardiac function dependent on a single energy source would be completely dependent on its availability. ${ }^{25}$

\section{Lipotoxicity}

The uptake of cardiac free fatty acids exceeds the oxidation capacity of these molecules. This leads to accumulation of triglycerides, cardiac steatosis and eventually death of cardiomyocytes, causing LV systolic dysfunction. This process has been demonstrated in animals and is called lipotoxicity. The change in energetic substrate, due to the reduction of insulin-mediated glucose uptake, also leads to diastolic dysfunction ${ }^{26}$. Generation of lipid intermediates, such as diacid-glycerol ${ }^{27}$, may be toxic to microcirculation, by effect on NO synthases and reduction of myocyte distensibility, as described above. Cardiac steatosis has also been associated with diastolic dysfunction in diabetic patients ${ }^{28}$.

Deposition of advanced glycation end products (AGEs)

AGEs are found in smooth muscle cells of the myocardial microcirculation ${ }^{16}$, as well as, in the extracellular matrix, between cardiomyocytes ${ }^{29}$. AGEs promote inflammation, extinguishing much of the NO produced locally. This would lead to a reduction in perfusion of the microcirculation at rest, but also of the coronary reserve during flow hyperemia. In addition, they trigger the production of reactive $\mathrm{O} 2$ species via NADPH oxidase, which may result in the activation of cellular apoptosis pathways and, therefore, systolic dysfunction ${ }^{30}$.

\section{Microvascular Rarefaction}

One of the most striking pathophysiological features of MCPDM is the reduction of microvascular myocardial perfusion and coronary flow reserve $\mathrm{e}^{31}$. This parameter is due to the action of AGEs in the microcirculation, but also due to rarefaction of capillaries and reduced luminal area/myocardial tissue ratio. Cardiomyocyte hypertrophy contributes to this result, raising the denominator of this ratio ${ }^{32}$. Capillary rarefaction per se reduces the bioavailability of NO to surrounding myocytes. Another result of this process is the relative tissue hypoxia associated with the production of reactive species of $\mathrm{O}^{2}$ and, finally, cell death and systolic dysfunction.

\section{Inflammatory/autoimmune Response}

Cardiac antimyosin autoantibodies were identified in type 1 diabetic patients after myocardial infarction and non-diabetic patients with autoimmune myocarditis. Diabetic patients, in general, present release of troponins that are related to HFEFr with dilatation of cardiac chambers. These findings may indicate that an autoimmune mechanism triggered by exposure to plasma troponin exists in the pathophysiology MCPDM with HFEFr ${ }^{33}$.

Autonomic neuropathy and renin-angiotensin-aldosterone system (RAAS)

Altered glucose metabolism and insulin resistance stimulate an excessive sympathetic activity 
BOARD 1. PATHOPHYSIOLOGICAL AND PATHOGENIC MECHANISMS OF DIABETIC CARDIOMYOPATHY

\begin{tabular}{|c|c|c|}
\hline \multicolumn{3}{|c|}{ Hyperglycemia - Insulin/hyperinsulinemia resistance } \\
\hline \multicolumn{3}{|c|}{ Cardiac insulin resistance and metabolic abnormalities (lipotoxicity) } \\
\hline $\begin{array}{l}\text { Mitochondrial } \\
\text { dysfunction }\end{array}$ & $\begin{array}{l}\text { Inflammation } \\
\text { (autoimmune } \\
\text { response) }\end{array}$ & $\begin{array}{l}\text { Autonomic } \\
\text { neuropathy }\end{array}$ \\
\hline Activation of RAAS & $\begin{array}{l}\text { Microvascular } \\
\text { dysfunction } \\
\text { Microcirculation } \\
\text { Rarefaction }\end{array}$ & AGEs \\
\hline $\begin{array}{l}\text { Inappropriate use of } \\
\text { mitochondrial } \mathrm{Ca} 2+\end{array}$ & Oxidative stress & $\begin{array}{l}\text { ER stress and cell } \\
\text { death }\end{array}$ \\
\hline \multicolumn{3}{|c|}{ Myocardial rigidity - Hypertrophy/Apoptosis - Interstitial fibrosis } \\
\hline \multicolumn{3}{|c|}{ Left ventricular diastolic/systolic dysfunction } \\
\hline
\end{tabular}

that is related to hypertrophy and cardiac fibrosis ${ }^{34}$. In the long term, cardiac sympathetic denervation occurs, a fact that impairs $\beta$-adrenergic signaling and reduces myocardial contractility, as well as disrupts the kinetics of relaxation and diastolic distensibility ${ }^{35,36}$. The myocardium of DM also presents upregulation of the RAAS and local endothelin ${ }^{37,38}$.

\section{CARDIAC PHENOTYPE}

Two types of cardiac phenotypes have been described for MCPDM ${ }^{39}$. The first pattern, apparently more common, is that of extracellular fibrosis, but with preserved sarcomere structure, reduced and hypertrophic left ventricle (LV), left atrial dilation, and diastolic dysfunction/restriction indicators; this pattern is clinically presented as HFEFp ${ }^{40}$ (Figure 1). The second pattern, reported in the earliest reports of MCPDM, is cardiomyocyte apoptosis and atrophy and loss of sarcomeric structure, scar replacement, cardiac chamber dilatation, and LV systolic dilatation/dysfunction clinically recognized as HFEFr (Figure 2). In both phenotypes, microcirculation rarefaction and microvascular deposition of advanced glycation end products (AGEs) are observed ${ }^{32}$.

TABLE 1: PATHOPHYSIOLOGICAL ASPECTS OF HFEFP AND HFEFR PHENOTYPES OF CMPDM ${ }^{39}$

\begin{tabular}{l|c|c} 
CMPDM & \multicolumn{1}{c}{$\begin{array}{c}\text { HFEFp/ } \\
\text { restrictive }\end{array}$} & $\begin{array}{c}\text { HFEFr/ } \\
\text { dilated }\end{array}$ \\
\hline Hyperglycemia & +++ & + \\
\hline Lipotoxicity & +++ & + \\
\hline Deposition of AGEs & +++ & +++ \\
\hline Microvascular rarefaction & +++ & +++ \\
\hline Inflammatory/autoimmune response & - & +++ \\
\hline Insulin resistance/Hyperinsulinemia & +++ & - \\
\hline
\end{tabular}

However, there is some controversy regarding the natural evolution of myocardial dysfunction and the interrelationship of these patterns, namely: some authors suggest that the pattern of diastolic dysfunction happens first and then develops into systolic dysfunction ${ }^{41}$; others argue that the phenotypes are independent and would be consequences of an individual response of each subject ${ }^{39}$. The latest evidence points to the second case. In a cohort of patients with $\mathrm{HF}$, it was observed that significant reductions of $\mathrm{EF}$ occur only in very old individuals ( $>80$ years old) or after the occurrence of heart attacks ${ }^{42}$ and therefore would be due to other factors not related to DM. Different phenotypic patterns imply the existence of corresponding distinct pathogens (Table 1). Thus, it is proposed that hyperglycemia, lipotoxicity and hyperinsulinemia/insulin resistance leading to microvascular coronary dysfunction are more important in the pathogenesis of CMPDM and HFEFp and that the inflammatory/autoimmune response would be more relevant for DMPDM and HFEFr.

\section{THERAPEUTIC MANAGEMENT - POSITIVE AND NEGATIVE EFFECTS OF HYPOGLYCEMIC AGENTS}

The treatment of MCPDM should follow the guidelines recommended according to the cardiac phenotype (HFEFr or HFEFp). However, evidence points to some peculiarities related to the class of drugs and its relation with MCPDM. For example, for the HFEFp phenotype, the use of beta-blockers is questionable and may even be deleterious, as it may lead to a worse clinical outcome, mediated by cardiac dysfunction, especially in women ${ }^{43}$. In addition, metformins have a beneficial effect by activation of adenosine monophosphate-activated protein kinase (MAPK) and increased bioavailability of NO, but there was no improvement in left ventricular diastolic function compared to pioglitazone ${ }^{44}$. As for sulfonylureas, they may potentially interfere with myocardial adaptive response to ischemia and are not recommended in this setting. Here are some other specificities of MCPDM treatment.

\section{Reduced glycemia}

Glycemic levels are associated with an increased risk of incident $\mathrm{HF}$, as well as atherothrombotic events in patients at risk or already with $\mathrm{DM}^{45}$. Thus, it is reasonable to conclude that the control 
of glycemic levels would reduce HF and CV events in this group of patients. In a meta-analysis including 27,049 participants from the Accord, Advance, UKPDS and Vadt studies, the authors demonstrate a $15 \%$ reduction in the relative risk of fatal/nonfatal AMI in patients with intensive glycemic control, but no reduction in hospitalization for HF, stroke, or other causes of death ${ }^{46}$. In a HF cohort, intensive blood glucose control in diabetic patients resulted in a worse outcome. In this study, patients who achieved HbA1c $\leq 7.2$ had an increased risk of death or urgently needed cardiac transplantation ${ }^{47}$. Another meta-analysis of more than 95 thousand individuals revealed that the treatment with hypoglycemic drugs increased the relative risk of $\mathrm{HF}$ in $14 \%$, exceeding in $5 \%$ the reduction of the relative risk of AMI in these patients ${ }^{48}$ and without any effect on mortality. One of the possible explanations connects to the metabolic inflexibility theory of cardiomyocytes. Stimulated entry of glucose into myocytes with reduced oxidation capacity of these molecules would lead to intracellular acidosis, resulting in reduction of the distensibility of the sarcomeric protein titin and diastolic dysfunction ${ }^{49}$.

\section{Peroxisome proliferator-activating receptor agonists- $\gamma$ (PPAR- $\gamma$ )}

However, the increased risk of HF generated by hypoglycemic drugs is surely linked to the specific action of each drug. This same meta-analysis demonstrated a high risk of HF related to the use of peroxisome proliferator-activating receptor agonists- $\gamma$ (PPAR- $\gamma$ ) (or thiazolidinediones) [risk ratio: $1.42(1.15-1.76)]^{48}$. These drugs provoke weight gain and water retention, impairing the hemodynamic condition of the patient with $\mathrm{HF}^{50,51}$. There is no reduction in cardiac systolic function ${ }^{51,52}$ using thiazolidinediones. The deleterious effect is likely to occur by stimulating renal tubular sodium reabsorption by signaling PPAR- $\gamma$ pathways dependent in these cells $^{53}$ consequent fluid retention. However, the simultaneous use of other diuretic drugs may counterbalance the observed weight and fluid gain. This has been demonstrated with the combination of pioglitazone dapaglifozin in a previous clinical trial ${ }^{54}$. In addition, one study suggests that pioglitazone reduces diastolic dysfunction in men with uncomplicated DM and absence of coronary disease ${ }^{44}$.

As with thiazolidinediones, dipeptidyl peptidase-4 inhibitors (iDPP-4) had a moderate risk of incident HF associated with its use unrelated to significant weight gain [risk ratio: 1.25 (1.08-1.45)] $]^{48}$ in the meta-analysis cited. On the other hand, the use of insulin glargine (Origin study) and weight loss by lifestyle change (Look-Ahead study), despite a favorable trend, had a neutral effect on the risk of HF.

\section{Inhibitors of dipeptidyl peptidase-4 (iDPP-4)}

In another meta-analysis $(\mathrm{n}=79,867)$ including only studies using iDPP-4 (which main randomized and controlled studies were Savor-Timi 53, Examine and Tecos), the authors demonstrate a $13 \%$ increase in HF $(p=0,03)$ after the introduction of the drugs of this class $\left(I^{2}=0 \%\right)$. The authors isolated only the main randomized controlled trials $(\mathrm{n}=36,543)$ (risk ratio $=1,14(0,97-1,32))$ and the risk remained, but they lost significance due to the large heterogeneity of the results $\left(I^{2}=42 \%\right)$. The Savor-Timi 53 study apparently carries the difference between results, leading to presuming that saxagliptin is the main drug (22\% increase in risk) in this class responsible for the incidence of HF - whereas sitagliptin would have no effect in this sense ${ }^{55}$. But, despite the large sample size, it has not yet been possible to determine with statistical certainty whether there is indeed a difference of effect within the iDPP-4 class (the sample was insufficient). Anyway, this is a worrying effect, because it happens mainly in populations that, for the most part, do not have previous history of HF.

IDPP-4 class drugs are easy to administer, do not cause weight gain or hypoglycaemia and have good gastrointestinal tolerability. However, they have potential cardiac and haemodynamic deleterious effects that may be exacerbated in patients with established or subclinical HF ${ }^{56}$. The DPP-4 enzyme is also responsible for degrading the stromal cell-derived factor (SDF) -1 [in addition to the peptides glucagon-like (GLP) -1]. The increase in SDF1, experimentally, channels mesenchymal cells to tissues undergoing overload or injury (for example myocardium) and promotes inflammation, regeneration, and fibrosis ${ }^{57}$. Another effect of SDF-1 is to increase sympathetic activity and to stimulate cyclic myocardial adenosine monophosphate (AMP-c), promoting hypertrophy and ventricular arrhythmias $^{58}$. Finally, the natriuretic effect of iDPP-4 is unobtrusive, not leading to weight loss, and appears to be the effect localized only to the distal portion of the renal tubules. ${ }^{59}$ The higher sodium reabsorption occurs, however, in the proximal tubules, which is 
why GLP-1 receptor agonists and sodium-glucose transporter inhibitors 2 (iSGLT2) have a greater diuretic effect: they act preferentially at this site ${ }^{60,61}$.

\section{Sodium-glucose transporter inhibitors 2 (iSGLT2)}

The Empa-REG Outcome clinical trial revealed an impressive relative risk reduction of $35 \%$ relative to the use of empaglifozine compared to the placebo group ${ }^{62}$ in patients with established cardiovascular disease. Curiously, the results are similar for patients with previous diagnosis of $\mathrm{HF}$ at the beginning of the study or not. Similar findings were found in the study that evaluated the effect of canagliptin on outcomes of $\mathrm{CV}^{63}$, a $32 \%$ reduction in hospitalizations due to HF. In parallel, "real world" results (>
180,000 patients) in a very broad population (United States and North America, Europe, the Middle East and Asia) corroborate these findings and add that this may be a class effect, as well as to be possible in individuals with no prior history of atherosclero$\operatorname{sis}^{64,65}$. The relative risk reduction of $\mathrm{HF}$, in this case compared to other hypoglycemic agents, was similar to that found in the Empa-REG and Canvas study, about $28 \%$.

The beneficial effects related to the use of these drugs are independent of the intensity of the glycemic reduction and may be related to significant weight loss and reduction of blood volume. However, other potential mechanisms are proposed. The use of empaglifozine deviates the use of glucose to fat

FIGURE 1: ECHOCARDIOGRAM OF PATIENT WITH CLINICAL HF AND PRESERVED LV EJECTION FRACTION

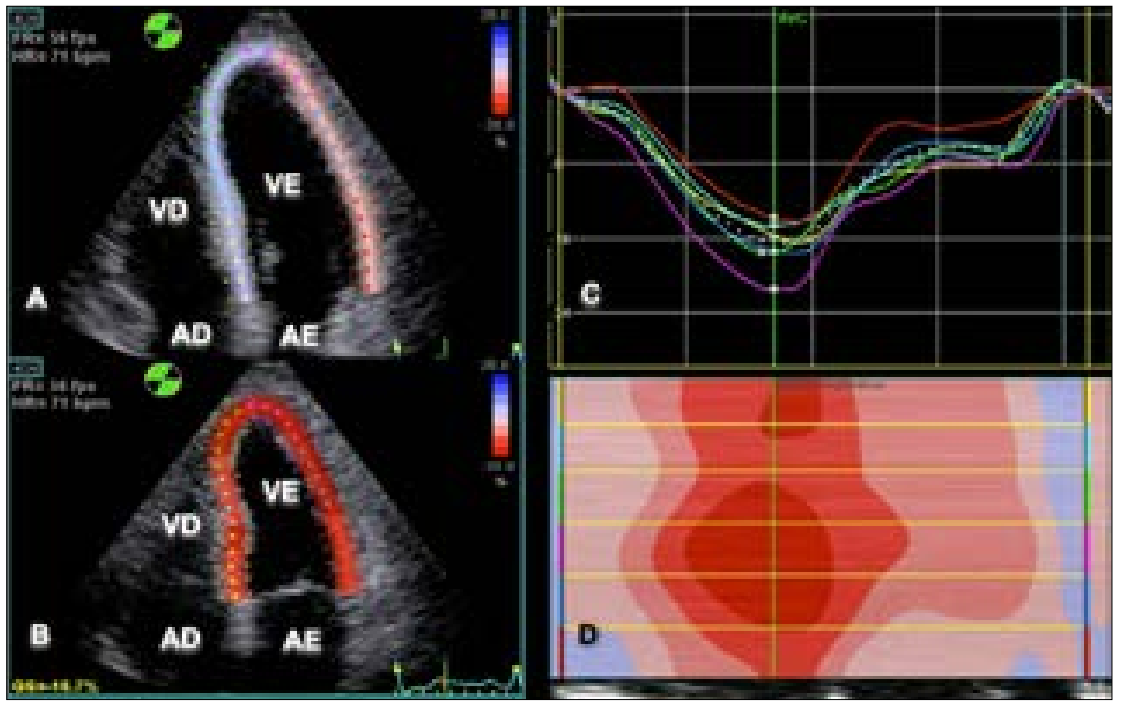

Panel A: left ventricle in diastole. Panel B: left ventricle in systole. Panel C: LV myocardial systolic longitudinal deformation, where each line represents a segment ( $Y$ axis) along the cardiac cycle.

Panel D: anatomic $M$ mode of the LV in the four-chamber window: the systolic deformation of each segment ( $y$-axis) is represented by color over time (x-axis), darker red tones are considered normal and abnormal, light tones.

$A D$ : right atrium;

AE: left atrium;

$\mathrm{RV}$ : right ventricle;

LV: left ventricle;

AVC: aortic valve closure

FIGURE 2: ECHOCARDIOGRAM OF PATIENT WITH CLINICAL HF AND REDUCED LV EJECTION FRACTION

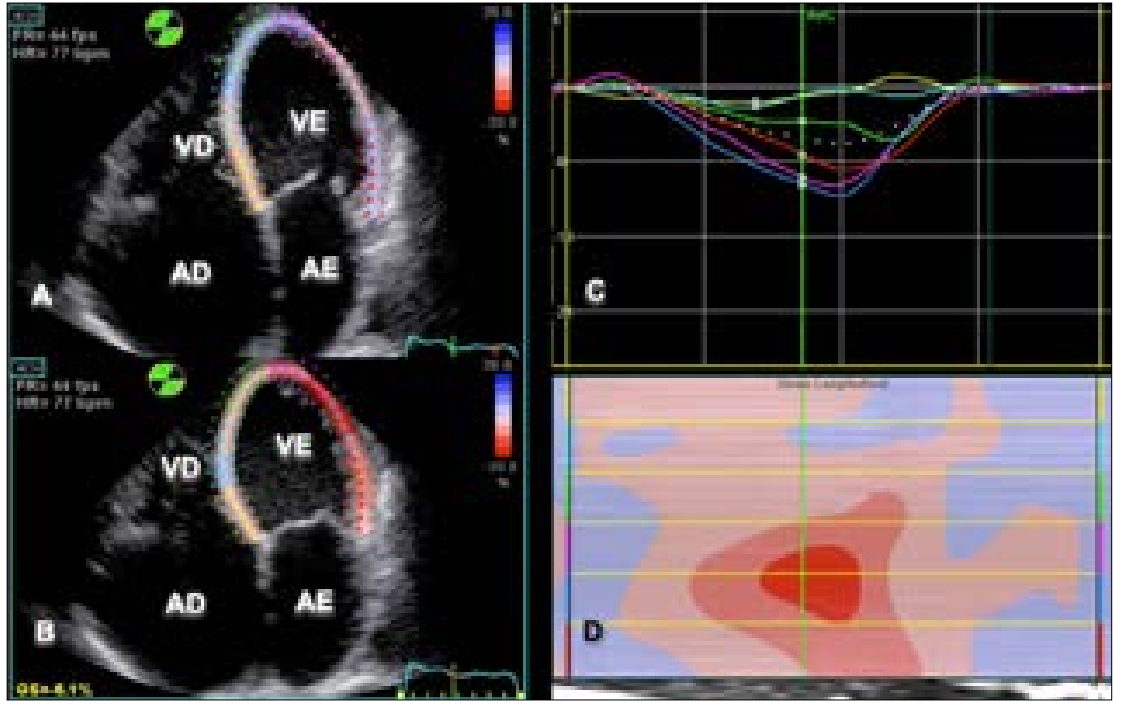

Panel A: left ventricle in diastole. Panel B: left ventricle in systole. Panel C: LV myocardial systolic longitudinal deformation, where each line represents a segment ( $Y$ axis) along the cardiac cycle.

Panel D: anatomic M mode of the LV in the four-chamber window: the systolic deformation of each segment (y-axis) is represented by color over time (x-axis), darker red tones are considered normal and abnormal, light tones.

$A D$ : right atrium;

AE: left atrium;

$R V$ : right ventricle;

LV: left ventricle;

AVC: aortic valve closure 
as an energetic substrate by the myocardium. The homeostatic balance favors the production of glucagon in relation to insulin and therefore the release of glucose and ketogenesis ${ }^{66}$. One of the products of ketogenesis, $\beta$-hydroxybutyrate, is associated with a reduction in myocardial glucose uptake. Possible positive effects of ketone bodies as an energetic substrate for the myocardium include resistance to oxidative stress, reduced lipolysis, lower metabolic rate, and reduced sympathetic tone ${ }^{67}$. At three months of treatment, there are also signs of mass reduction and recovery of LV distensibility ${ }^{68}$. Other pathways in which iSGLT2 may hinder the establishment of MCPDM include: reduction of insulin resistance, blood pressure, albuminuria and uric acid, attenuation of arterial stiffness, inflammation, oxidative stress and sympathetic hyperactivity, and regulation for angiotensin receptor blockers.

Insulin

Intensive insulin use does not appear to reduce $\mathrm{LV}$ diastolic dysfunction in patients with MCPDM.
Despite some disagreement between studies, some suggesting positive results ${ }^{69}$ and others not, there is no evidence of improvement of left ventricular relaxation with intense glycemic control through the use of insulin ${ }^{70}$. The potential benefit of glycemic control may be counterbalanced by weight gain promoted by insulin use.

\section{FINAL COMMENTS}

MCPDM is a complex and difficult diagnosis condition. Its recognition has been dubious due to the simultaneity of pathogenic effects promoted by diseases and associated CV risk factors. However, the evidence has increasingly made clear the pathophysiology and clinical presentation of this cardiomyopathy, as well as demonstrated that its validity may worsen the prognosis of coexisting diseases. Many aspects of MCPDM are not yet understood, so awareness of diagnosis is necessary in the care and academic circles to create mechanisms to attenuate their ominous repercussions.

\section{RESUMO}

Apesar de há muito tempo descrita, não existe consenso estabelecido quanto à real existência da cardiomiopatia diabética (CMPDM). Devido à sua complexa fisiopatologia, tem sido árduo à pesquisa clínica e experimental estabelecer conexões claras entre diabetes mellitus (DM) e insuficiência cardíaca (IC), assim como solucionar os mecanismos da doença subjacente do miocárdio. No entanto, as evidências epidemiológicas da relação dessas condições são incontestáveis. O interesse em compreender melhor essa doença tem recrudescido devido aos recentes resultados de ensaios clínicos avaliando novos fármacos hipoglicemiantes, como os inibidores do transportador de sódio-glicose 2, que demonstraram respostas favoráveis, considerando-se a prevenção e tratamento da IC em pacientes portadores de DM. Nesta revisão, percorremos aspectos da epidemiologia da CMPDM e de seus possíveis mecanismos patogênicos, além de apresentarmos os principais fenótipos cardíacos da CMPDM (IC com fração de ejeção preservada e reduzida) e implicações do manejo terapêutico desta doença.

PALAVRAS-CHAVE: Diabetes mellitus. Cardiomiopatias. Hipoglicemiantes. Insuficiência cardíaca.

\section{REFERENCES}

1. Ryden L, Armstrong PW, Cleland IG, Horowitz ID, Massie BM, Packer M et al. Efficacy and safety of high-dose lisinopril in chronic heart failure patients at high cardiovascular risk, including those with diabetes mellitus. Results from the ATLAS trial. Eur Heart J. 2000;21(23):1967-78.

2. Shindler DM, Kostis JB, Yusuf S, Quinones MA, Pitt B, Stewart D, et al. Diabetes mellitus, a predictor of morbidity and mortality in the Studies of Left Ventricular Dysfunction (SOLVD) Trials and Registry. Am J Cardiol. 1996;77(11):1017-20.

3. Thrainsdottir IS, Aspelund T, Thorgeirsson G, Gudnason V, Hardarson T, Malmberg $\mathrm{K}$, et al. The association between glucose abnormalities and heart failure in the population-based Reykjavik study. Diabetes Care. 2005;28(3):612-6.

4. Suskin N, McKelvie RS, Burns RJ, Latini R, Pericak D, Probstfield ), et al. Glucose and insulin abnormalities relate to functional capacity in patients with congestive heart failure. Eur Heart J. 2000;21(16):1368-75.

5. Domanski M, Krause-Steinrauf $H$, Deedwania P, Follmann D, Ghali JK, Gilbert E, et al. The effect of diabetes on outcomes of patients with advanced heart failure in the BEST trial. J Am Coll Cardiol. 2003;42(5):914-22.
6. MacDonald MR, Petrie MC, Varyani F, Ostergren J, Michelson EL, Young $J B$, et al. Impact of diabetes on outcomes in patients with low and preserved ejection fraction heart failure: an analysis of the Candesartan in Heart failure: Assessment of Reduction in Mortality and morbidity (CHARM) programme. Eur Heart J. 2008;29(11):1377-85.

7. Kannel WB, Hjortland M, Castelli WP. Role of diabetes in congestive heart failure: the Framingham study. Am J Cardiol. 1974;34(1):29-34.

8. Iribarren C, Karter AJ, Go AS, Ferrara A, Liu JY, Sidney S, et al. Glycemic control and heart failure among adult patients with diabetes. Circulation. 2001;103(22):2668-73.

9. Stratton IM, Adler Al, Neil HA, Matthews DR, Manley SE, Cull CA, et al. Association of glycaemia with macrovascular and microvascular complications of type 2 diabetes (UKPDS 35): prospective observational study. BMJ. 2000;321(7258):405-12.

10. Aguilar D, Bozkurt B, Ramasubbu K, Deswal A. Relationship of hemoglobin $\mathrm{A} 1 \mathrm{C}$ and mortality in heart failure patients with diabetes. J Am Coll Cardiol. 2009;54(5):422-8.

11. Goode KM, John J, Rigby AS, Kilpatrick ES, Atkin SL, Bragadeesh T, et al. Elevated glycated haemoglobin is a strong predictor of mortality in pa- 
tients with left ventricular systolic dysfunction who are not receiving treatment for diabetes mellitus. Heart. 2009;95(11):917-23.

12. Eshaghian S, Horwich TB, Fonarow GC. An unexpected inverse relationship between $\mathrm{HbA1c}$ levels and mortality in patients with diabetes and advanced systolic heart failure. Am Heart J. 2006;151(1):91.

13. Shenouda SM, Widlansky ME, Chen K, Xu G, Holbrook M, Tabit CE, et al. Altered mitochondrial dynamics contributes to endothelial dysfunction in diabetes mellitus. Circulation. 2011;124(4):444-53.

14. van Heerebeek L, Hamdani N, Falcão-Pires I, Leite-Moreira AF, Begieneman MP, Bronzwaer JG, et al. Low myocardial protein kinase $G$ activity in heart failure with preserved ejection fraction. Circulation. 2012;126(7):8309.

15. Hamdani N, Franssen C, Lourenço A, Falcão-Pires I, Fontoura D, Leite S, et al. Myocardial titin hypophosphorylation importantly contributes to heart failure with preserved ejection fraction in a rat metabolic risk model. Circ Heart Fail. 2013;6(6):1239-49.

16. Falcão-Pires I, Hamdani N, Borbely A, Gavina C, Schalkwijk CG, van der Velden ], et al. Diabetes mellitus worsens diastolic left ventricular dysfunction in aortic stenosis through altered myocardial structure and cardiomyocyte stiffness. Circulation. 2011;124(10):1151-9.

17. Asbun J, Villarreal FJ. The pathogenesis of myocardial fibrosis in the setting of diabetic cardiomyopathy. I Am Coll Cardiol. 2006;47(4):693-700.

18. Slawson C, Copeland RJ, Hart GW. O-GlcNAc signaling: a metabolic link between diabetes and cancer? Trends Biochem Sci. 2010;35(10):547-55.

19. Qin CX, Sleaby R, Davidoff AJ, Bell JR, De Blasio MJ, Delbridge LM, et al Insights into the role of maladaptive hexosamine biosynthesis and $\mathrm{O}-\mathrm{Gl}$ NAcylation in development of diabetic cardiac complications. Pharmaco Res. 2017;116:45-56.

20. Murray AJ, Anderson RE, Watson GC, Radda GK, Clarke K. Uncoupling proteins in human heart. Lancet. 2004;364(9447):1786-8.

21. Boudina S, Abel ED. Mitochondrial uncoupling: a key contributor to reduced cardiac efficiency in diabetes. Physiology (Bethesda). 2006;21:250-

22. Kruger M, Babicz K, von Frieling-Salewsky M, Linke WA. Insulin signaling regulates cardiac titin properties in heart development and diabetic cardiomyopathy. I Mol Cell Cardiol. 2010;48(5):910-6.

23. Dutka DP, Pitt M, Pagano D, Mongillo M, Gathercole D, Bonser RS, et al. Myocardial glucose transport and utilization in patients with type 2 diabetes mellitus, left ventricular dysfunction, and coronary artery disease. I Am Coll Cardiol. 2006;48(11):2225-31.

24. Mather KJ, Hutchins GD, Perry K, Territo W, Chisholm R, Acton A, et al. Assessment of myocardial metabolic flexibility and work efficiency in human type 2 diabetes using 16-[18F]fluoro-4-thiapalmitate, a novel PET fatty acid tracer. Am J Physiol Endocrinol Metab. 2016;310(6):E452-60.

25. Tuunanen $H$, Engblom E, Naum A, Någren $K$, Hesse B, Airaksinen KE, et al. Free fatty acid depletion acutely decreases cardiac work and efficiency in cardiomyopathic heart failure. Circulation. 2006;114(20):2130-7.

26. Rijzewijk LI, van der Meer RW, Lamb HJ, Jong HW, Lubberink M, Romijn A, et al. Altered myocardial substrate metabolism and decreased diastolic function in nonischemic human diabetic cardiomyopathy: studies with cardiac positron emission tomography and magnetic resonance imaging. Am Coll Cardiol. 2009;54(16):1524-32.

27. Zhang L, Ussher JR, Oka T, Cadete VJ, Wagg C, Lopaschuk GD. Cardiac diacylglycerol accumulation in high fat-fed mice is associated with impaired insulin-stimulated glucose oxidation. Cardiovasc Res 2011;89(1):148-56.

28. Rijzewijk LJ, van der Meer RW, Smit JW, Diamant M, Bax JJ, Hammer S, et al. Myocardial steatosis is an independent predictor of diastolic dysfunction in type 2 diabetes mellitus. J Am Coll Cardiol. 2008;52(22):1793-9.

29. Donaldson C, Taatjes DI, Zile M, Palmer B, VanBuren P, Spinale F, et al. Combined immunoelectron microscopic and computer-assisted image analyses to detect advanced glycation end-products in human myocardium. Histochem Cell Biol. 2010;134(1):23-30.

30. Zhang M, Kho AL, Anilkumar N, Chibber R, Pagano PJ, Shah AM, et al. Glycated proteins stimulate reactive oxygen species production in cardiac myocytes: involvement of Nox2 (gp91phox)-containing NADPH oxidase. Circulation. 2006;113(9):1235-43.

31. Camici PG, Crea F. Coronary microvascular dysfunction. N Engl | Med. 2007;356(8):830-40

32. van Heerebeek L, Hamdani N, Handoko ML, Falcão-Pires I, Musters RI, Kupreishvili K, et al. Diastolic stiffness of the failing diabetic heart: importance of fibrosis, advanced glycation end products, and myocyte resting tension. Circulation. 2008;117(1):43-51.
33. Selvin E, Lazo M, Chen Y, Shen L, Rubin J, McEvoy JW, et al. Diabetes mellitus, prediabetes, and incidence of subclinical myocardial damage. Circulation. 2014;130(16):1374-82

34. Masuo K, Rakugi H, Ogihara T, Esler MD, Lambert GW. Cardiovascular and renal complications of type 2 diabetes in obesity: role of sympathetic nerve activity and insulin resistance. Curr Diabetes Rev. 2010;6(2):58-67.

35. Schnell O, Kirsch CM, Stemplinger J, Haslbeck M, Standl E. Scintigraphic evidence for cardiac sympathetic dysinnervation in long-term IDDM patients with and without ECG-based autonomic neuropathy. Diabetologia. 1995;38(11):1345-52

36. Schnell O, Muhr D, Weiss M, Dresel S, Haslbeck M, Standl E. Reduced myocardial 1231-metaiodobenzylguanidine uptake in newly diagnosed IDDM patients. Diabetes. 1996;45(6):801-5.

37. Kumar R, Yong QC, Thomas CM, Baker KM. Intracardiac intracellular angiotensin system in diabetes. Am | Physiol Regul Integr Comp Physiol. 2012;302(5):R510-7.

38. Di Carli MF, Janisse J, Grunberger G, Ager J. Role of chronic hyperglycemia in the pathogenesis of coronary microvascular dysfunction in diabetes. J Am Coll Cardiol. 2003;41(8):1387-93.

39. Seferovic PM, Paulus WJ. Clinical diabetic cardiomyopathy: a twofaced disease with restrictive and dilated phenotypes. Eur Heart 2015;36(27):1718-27, 27a-27c

40. Marwick TH, Ritchie R, Shaw JE, Kaye D. Implications of underlying mechanisms for the recognition and management of diabetic cardiomyopathy. J Am Coll Cardiol. 2018;71(3):339-51.

41. Fang $Z Y$, Prins JB, Marwick TH. Diabetic cardiomyopathy: evidence, mechanisms, and therapeutic implications. Endocr Rev. 2004;25(4):54367.

42. Dunlay SM, Roger VL, Weston SA, Jiang R, Redfield MM. Longitudinal changes in ejection fraction in heart failure patients with preserved and reduced ejection fraction. Circ Heart Fail. 2012;5(6):720-6.

43. Farasat SM, Bolger DT, Shetty V, Menachery EP, Gerstenblith G, Kasper EK, et al. Effect of beta-blocker therapy on rehospitalization rates in women versus men with heart failure and preserved ejection fraction. Am J Cardiol. 2010;105(2):229-34

44. van der Meer RW, Rijzewijk LI, de Jong HW, Lamb HJ, Lubberink M, Romijn JA, et al. Pioglitazone improves cardiac function and alters myocardial substrate metabolism without affecting cardiac triglyceride accumulation and high-energy phosphate metabolism in patients with well-controlled type 2 diabetes mellitus. Circulation. 2009;119(15):2069-77.

45. Rao Kondapally Seshasai S, Kaptoge S, Thompson A, Di Angelantonio E, Gao P, Sarwar N, et al. Diabetes mellitus, fasting glucose, and risk of cause-specific death. N Engl | Med. 2011;364(9):829-41.

46. Control G, Turnbull FM, Abraira C, Anderson RJ, Byington RP, Chalmers JP, et al. Intensive glucose control and macrovascular outcomes in type 2 diabetes. Diabetologia. 2009;52(11):2288-98.

47. Tomova GS, Nimbal V, Horwich TB. Relation between hemoglobin a(1c) and outcomes in heart failure patients with and without diabetes mellitus. Am | Cardiol. 2012;109(12):1767-73.

48. Udell JA, Cavender MA, Bhatt DL, Chatterjee S, Farkouh ME, Scirica BM. Glucose-lowering drugs or strategies and cardiovascular outcomes in patients with or at risk for type 2 diabetes: a meta-analysis of randomised controlled trials. Lancet Diabetes Endocrinol. 2015;3(5):356-66.

49. Kotter S, Unger A, Hamdani N, Lang P, Vorgerd M, Nagel-Steger L, et al. Human myocytes are protected from titin aggregation-induced stiffening by small heat shock proteins. J Cell Biol 2014;204(2):187-202.

50. Nesto RW, Bell D, Bonow RO, Fonseca V, Grundy SM, Horton ES, et al. Thiazolidinedione use, fluid retention, and congestive heart failure: a consensus statement from the American Heart Association and American Diabetes Association. October 7, 2003. Circulation. 2003;108(23):2941-8.

51. Shah M, Kolandaivelu A, Fearon WF. Pioglitazone-induced heart failure despite normal left ventricular function. Am J Med. 2004;117(12):973-4.

52. St John Sutton M, Rendell M, Dandona P, Dole JF, Murphy K, Patwardhan $R$, et al. A comparison of the effects of rosiglitazone and glyburide on cardiovascular function and glycemic control in patients with type 2 diabetes. Diabetes Care. 2002;25(11):2058-64.

53. Zhang H, Zhang A, Kohan DE, Nelson RD, Gonzalez F), Yang T. Collecting duct-specific deletion of peroxisome proliferator-activated receptor gamma blocks thiazolidinedione-induced fluid retention. Proc Natl Acad Sci U S A. 2005;102(26):9406-11.

54. Rosenstock J, Vico M, Wei L, Salsali A, List JF. Effects of dapagliflozin, an SGLT2 inhibitor, on $\mathrm{HbA}(1 \mathrm{c})$, body weight, and hypoglycemia risk in pa- 
tients with type 2 diabetes inadequately controlled on pioglitazone monotherapy. Diabetes Care. 2012;35(7):1473-8.

55. Verma S, Goldenberg RM, Bhatt DL, Farkouh ME, Quan A, Teoh H, et al. Dipeptidyl peptidase-4 inhibitors and the risk of heart failure: a systematic review and meta-analysis. CMAJ Open. 2017;5(1):E152-E77.

56. Packer M. Worsening heart failure during the use of DPP-4 inhibitors: pathophysiological mechanisms, clinical risks, and potential influence of concomitant antidiabetic medications. JACC Heart Fail. 2018;6(6):445-51.

57. Chu PY, Mariani J, Finch S, McMullen JR, Sadoshima J, Marshall T, et al. Bone marrow-derived cells contribute to fibrosis in the chronically failing heart. Am J Pathol. 2010;176(4):1735-42.

58. Miyoshi T, Nakamura K, Yoshida M, Miura D, Oe H, Akagi S, et al. Effect of vildagliptin, a dipeptidyl peptidase 4 inhibitor, on cardiac hypertrophy induced by chronic beta-adrenergic stimulation in rats. Cardiovasc Diabetol. 2014;13:43.

59. Lovshin JA, Rajasekeran H, Lytvyn Y, Lovblom LE, Khan S, Alemu R, et al. Dipeptidyl peptidase 4 inhibition stimulates distal tubular natriuresis and increases in circulating SDF-1alpha(1-67) in patients with type 2 diabetes. Diabetes Care. 2017;40(8):1073-81.

60. Ghezzi C, Yu AS, Hirayama BA, Kepe V, Liu J, Scafoglio C, et al. Dapagliflozin binds specifically to sodium-glucose cotransporter 2 in the proximal renal tubule. J Am Soc Nephrol. 2017;28(3):802-10.

61. Muskiet MHA, Tonneijck L, Smits MM, van Baar MJB, Kramer MHH, Hoorn EJ, et al. GLP-1 and the kidney: from physiology to pharmacology and outcomes in diabetes. Nat Rev Nephrol. 2017;13(10):605-28.

62. Zinman B, Wanner C, Lachin JM, Fitchett D, Bluhmki E, Hantel S, et al. Empagliflozin, cardiovascular outcomes, and mortality in type 2 diabetes. N Engl J Med. 2015;373(22):2117-28.

63. Neal B, Perkovic V, Mahaffey KW, Zeeuw D, Fulcher G, Erondu N, et al.
Canagliflozin and cardiovascular and renal events in type 2 diabetes. $\mathrm{N}$ Engl | Med. 2017;377(7):644-57.

64. Kosiborod M, Lam CSP, Kohsaka S, Kim DJ, Karasik A, Shaw J, et al. Cardiovascular events associated with SGLT-2 inhibitors versus other glucose-lowering drugs: the CVD-REAL 2 study. I Am Coll Cardiol. 2018;71(23):2628-39.

65. Kosiborod M, Cavender MA, Fu AZ, Wilding JP, Khunti K, Holl RW, et al. Lower risk of heart failure and death in patients initiated on sodium-glucose cotransporter-2 inhibitors versus other glucose-lowering drugs: the CVD-REAL study (Comparative effectiveness of cardiovascular outcomes in new users of sodium-glucose cotransporter-2 inhibitors). Circulation. 2017;136(3):249-59.

66. Ferrannini E, Baldi S, Frascerra S, Astiarraga B, Heise T, Bizzotto R, et al. Shift to fatty substrate utilization in response to sodium-glucose cotransporter 2 inhibition in subjects without diabetes and patients with type 2 diabetes. Diabetes. 2016;65(5):1190-5.

67. Newman JC, Verdin E. Ketone bodies as signaling metabolites. Trends Endocrinol Metab. 2014;25(1):42-52

68. Verma S, Garg A, Yan AT, Gupta AK, Al-Omran M, Sabongui A, et al. Effect of empagliflozin on left ventricular mass and diastolic function in individuals with diabetes: an important clue to the EMPA-REG OUTCOME trial? Diabetes Care. 2016;39(12):e212-e3.

69. von Bibra $H$, Hansen A, Dounis V, Bystedt $T$, Malmberg K, Ryden L. Augmented metabolic control improves myocardial diastolic function and perfusion in patients with non-insulin dependent diabetes. Heart. 2004;90(12):1483-4.

70. Jarnert C, Landstedt-Hallin L, Malmberg K, Melcher A, Ohrvik J, Persson $\mathrm{H}$, et al. A randomized trial of the impact of strict glycaemic control on myocardial diastolic function and perfusion reserve: a report from the DADD (Diabetes mellitus And Diastolic Dysfunction) study. Eur | Heart Fail. 2009;11(1):39-47. 